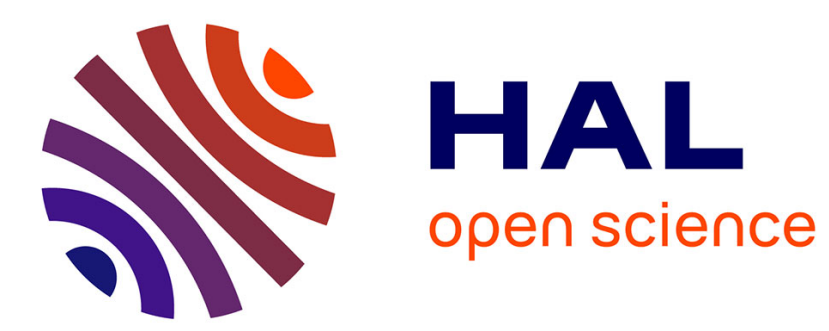

\title{
Macroecology of seed banks: The role of biogeography, environmental stochasticity and sampling
}

\author{
Franck Jabot, Julien Pottier
}

\section{To cite this version:}

Franck Jabot, Julien Pottier. Macroecology of seed banks: The role of biogeography, environmental stochasticity and sampling. Global Ecology and Biogeography, 2017, 26 (11), pp.1247-1257. 10.1111/geb.12631 . hal-01635210

\section{HAL Id: hal-01635210 https://hal.science/hal-01635210}

Submitted on 14 Nov 2017

HAL is a multi-disciplinary open access archive for the deposit and dissemination of scientific research documents, whether they are published or not. The documents may come from teaching and research institutions in France or abroad, or from public or private research centers.
L'archive ouverte pluridisciplinaire HAL, est destinée au dépôt et à la diffusion de documents scientifiques de niveau recherche, publiés ou non, émanant des établissements d'enseignement et de recherche français ou étrangers, des laboratoires publics ou privés. 


\section{Macroecology of seed banks: The role of biogeography, environmental stochasticity and sampling}

\section{Franck Jabot ${ }^{1}$ (1) | Julien Pottier ${ }^{2}$}

${ }^{1}$ Irstea, UR LISC, Campus des Cézeaux, Aubiere, France

${ }^{2}$ INRA, UR874 (Unité de Recherche sur I'Ecosystème Prairial), Clermont-Ferrand, France

\section{Correspondence}

Franck Jabot, Irstea, UR LISC, Campus des Cézeaux, 9 avenue Blaise Pascal, CS 20085, Aubiere 63178, France.

Email: franck.jabot@irstea.fr

Editor: Brian Enquist

\begin{abstract}
Aim: The study of seed banks has been mainly conducted at local scales, thereby hampering our general understanding of the assembly processes of these biodiversity reservoirs. Here, we aim to document worldwide macroecological patterns of seed bank diversity and of their similarity with aboveground vegetation. Our second aim is to investigate the likely drivers of these macroecological patterns and to lay the foundation of a metacommunity theory of seed banks.

Location: Worldwide.
\end{abstract}

Time period: $1989-2005$.

Major taxa studied: Plants.

Methods: We compiled a worldwide dataset of 130 seed banks located in grasslands. We assessed the likely drivers of seed bank diversity and similarity with aboveground vegetation, using structural equation modelling. We then developed a time-averaged neutral model of coupled seed bank-vegetation (S-V) dynamics that includes the effect of environmental stochasticity, and we compared its predictions with empirical findings.

Results: We found evidence for two weak latitudinal gradients in seed bank diversity and S-V similarity, with larger species richness and smaller similarity closer to the tropics. We then showed that seed bank richness and S-V similarity are correlated with the following four distinct drivers: local environmental variability, plant regional diversity, seed bank density and sampling area. Finally, we showed that the predictions of the time-averaged neutral model are remarkably in accord with empirical observations.

Main conclusions: Our results lay the foundations of a metacommunity theory for seed banks. They challenge the standard view that seed banks are principally structured by environmental variability, by highlighting the additional key roles of dispersal and stochastic sampling on seed bank diversity patterns.

\section{KEYWORDS}

demographic stochasticity, environmental stochasticity, grassland, latitudinal gradient, metacommunity, regional pool, sampling intensity, time-averaged neutral model

\section{1 | INTRODUCTION}

Seed banks have attracted the interest of many vegetation ecologists over the years (Baskin \& Baskin, 2001). Numerous studies have documented seed bank diversity, density and their similarity with standing vegetation, in order to understand how seed banks may influence the regeneration and dynamics of plant communities (Bossuyt \& Honnay, 2008; Hopfensperger, 2007), with implications in ecological restoration and conservation (Bakker \& Berendse, 1999). In addition, theories on the impacts of seed banks on local community dynamics have been developed and tested (e.g., Bonis, Lepart, \& Grillas, 1995; Pake \& Venable, 1996; Warner \& Chesson, 1985). Seed bank dynamics result 
from the balance between seed rain, germination and persistence. Seed bank patterns have therefore been linked to local disturbance regime (Henderson, Petersen, \& Redak, 1988), successional ages (Bekker, Verweij, Bakker, \& Fresco, 2000), seed longevity (Thompson, Bakker, \& Bekker, 1997) and historical factors, such as past land use (Bossuyt \& Hermy, 2001), and compared between different types of habitats (Hopfensperger, 2007).

In contrast, the influences of large-scale biogeographical factors and sampling issues have been poorly investigated (Vandvik, Klanderud, Meineri, Måren, \& Töpper, 2015). Immigrating propagules from surrounding areas contribute to the seed rain. Quantifying the importance of such immigration events is a long-standing research challenge, but accumulating evidence suggests that long-distance dispersal events do influence local assembly processes (Jones \& Muller-Landau 2008; Jordano 2017). Consequently, the diversity of local seed banks should be positively influenced by the diversity of the regional flora. Besides, denser seed banks should tend to harbour larger diversity owing to a sampling effect. Such sampling effects are generally overlooked when comparing different seed bank samples, so that a rigorous framework to assess seed bank diversity patterns is needed (Vandvik et al., 2015). Such a framework would enable the assessment of the respective influences of local, regional and sampling processes on seed bank assembly.

From a more theoretical perspective, there has been no attempt to mobilize existing macroecological theories to shed light on seed bank patterns. Among such theories, neutral theory has received much attention from ecologists over the past 15 years (Hubbell, 2001; Rosindell, Hubbell, \& Etienne, 2011). It attempts to understand community assembly, dynamics and evolution based on the combination of stochastic processes and limited dispersal. By providing a clear quantitative framework, neutral theory has reinvigorated many previously loose visions of ecosystems that were based on the unique lens of deterministic processes without rigorous justifications (e.g., Jabot \& Chave, 2011; McGill, Etienne, \& Gray, 2007; Plotkin et al., 2000). In this vein, neutral predictions have been compared with various community patterns, including species-abundance distributions (Volkov, Banavar, Hubbell, \& Maritan, 2003), species spatial turnover (Condit, Pitman, \& Leigh, 2002), community phylogenetic structure (Jabot \& Chave, 2009) and community dynamics (Kalyuzhny, Kadmon, \& Shnerb, 2015).

The neutral-based vision of community assembly and dynamics has not yet penetrated the field of seed bank ecology. This is not surprising, because this field has been structured around the two building ideas of species-specific responses to environmental variations (Facelli, Chesson, \& Barnes, 2005; Grubb, 1977; Warner \& Chesson, 1985) and of bet-hedging (Slatkin, 1974; Venable, 2007), which may appear at first sight to be fundamentally opposed to neutral assumptions. The recent development of time-averaged neutral models (Jabot \& Lohier, 2016; Kalyuzhny et al., 2015) opens a new opportunity to build a neutral-based quantitative assessment of seed ecological patterns. Indeed, time-averaged neutral models relax the strong assumption of constant competitive equivalence among individuals and replace it by a weaker assumption of time-averaged competitive equivalence among individuals (Kalyuzhny et al., 2015). In such models, different individuals may have different demographic rates at each time step, but their lifetime average expectancy in demographic rates is constant. This relaxed form of equivalence among individuals enables the construction of a simple and operational quantitative framework to analyse seed bank community patterns, without ignoring well-established biological evidence surrounding plant regeneration niches (Grubb, 1977).

In strictly neutral models, although all individuals of a community have the same probability of realizing demographic events such as birth, death, reproduction and dispersal, there is some level of interindividual variability in the effective realizations of these demographic events, owing to chance. This inter-individual variability is generally called demographic stochasticity, and it can lead to some level of unevenness in species abundances by ecological drift (Hubbell, 2001). Chance variability may also occur during the random sampling of a community, an idea already present in the literature on rarefaction (Heck, van Belle, \& Simberloff, 1975) and null models (Gotelli \& Graves, 1996). Its consequences on seed bank patterns have recently been stressed (Vandvik et al., 2015). On top of demographic and sampling variabilities, time-averaged neutral models consider that there is some level of inter-individual variability in their probability of realizing demographic events at each time step, although they all have the same timeaveraged demographic probabilities. This last source of inter-individual variability is generally called environmental stochasticity in the literature (Ives, Dennis, Cottingham, \& Carpenter, 2003; Lande, Engen, \& Saether, 2003). It is an operational way to model the temporal environmental variability encountered by plant individuals and seed banks without explicitly modelling environmental variables (Chesson, 2000). Consequently, standard and time-averaged neutral models should enable the assessment of whether empirically observed seed bank macroecological patterns may be explained by the combined action of demographic and sampling stochasticity (strict neutrality), whether the inclusion of environmental stochasticity is necessary (time-averaged neutrality) or whether additional deterministic processes need to be invoked to explain seed ecological patterns.

In this study, we aim at (a) assessing the respective roles of local, regional and sampling processes in the assembly of seed banks and at (b) comparing observed seed bank patterns with predictions of strictly neutral and time-averaged neutral models. We focus on two macroecological patterns of (a) seed bank diversity and (b) seed bank-vegetation (S-V) similarity. These two seed bank characteristics are among the most commonly studied and are therefore amenable to generalization. We first compile empirical evidence for seed bank macroecological patterns from published studies and assess, using structural equation modelling, the influence of the following four drivers: local environmental variability, plant regional diversity, seed bank density and sampling area. The first driver relates to the standard vision of a seed bank assembly controlled by environmental variability; the second driver relates to a metacommunity view of seed bank assembly; and the last two drivers relate to stochastic and sampling processes. Sampling area can be seen here as a nuisance variable rather than a genuine ecological driver. It was included to control for the influence of variable sampling protocols among empirical studies. We then develop a 

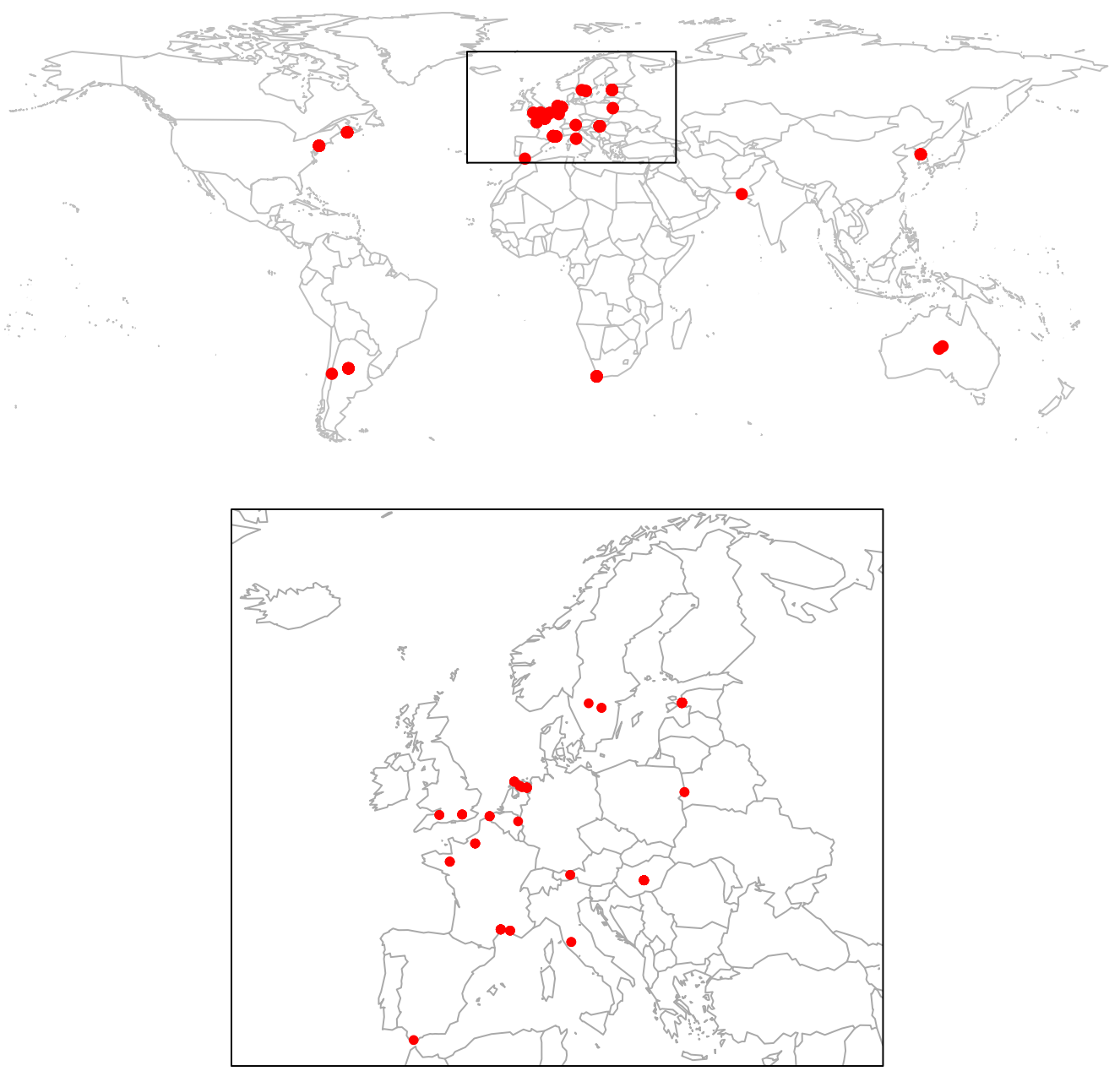

FIGURE 1 Location of field studies documenting seed bank-vegetation similarities in grasslands

time-averaged neutral model with a seed bank to establish neutral predictions regarding these patterns. Comparing neutral predictions with empirical evidence enables us to assess the likely drivers of seed bank macroecological patterns.

\section{2 | METHODS}

\section{1 | Data compilation}

We compiled the grassland studies mentioned in the meta-analysis of Hopfensperger (2007) and retained those that had information on seed bank density. We restricted our compilation to grassland studies, because forests and wetlands present additional complexities, such as mast seeding and flooding events. This led to a number of 29 studies, altogether reporting 130 values of seed bank diversity, density and similarity with standing vegetation, and sampling a wide array of grassland types (Figure 1). In these empirical studies, plants and seeds were sampled locally at spatial scales ranging from 0.4 to $7,500 \mathrm{~m}^{2}$ for plants and from 0.02 to $1.41 \mathrm{~m}^{2}$ for seeds (Supporting Information Appendix S1). Seed bank-vegetation similarity was calculated following the Sorensen formulation for presence-absence data as in most empirical studies, and sampling area was estimated as the total area sampled for seed bank assessment. Two types of covariables were further compiled: (a) the regional pool richness retrieved from the global map of vascular plants (Ellis, Antill, \& Kreft, 2012; Kreft \& Jetz, 2007), and (b) climatic variability calculated as the coefficient of variation of the annual number of wet days in the period 1901-2009 that was retrieved from the CRU v3.10 database (Harris, Jones, Osborn, \& Lister, 2014). Preliminary analyses indeed revealed that this environmental predictor was the most correlated with seed bank patterns, among other climatic parameters available from this database. The full dataset, including seed bank patterns and covariables, is provided in Supporting Information Appendix S2.

\subsection{Structural equation modelling}

We used structural equation modelling to assess the correlations between seed bank patterns (richness and S-V similarity) and the four drivers: seed bank density, sampling area, plant regional pool richness and climatic variability (coefficient of variation of the number of wet days). In the structural equation model, the indirect effects of the drivers on S-V similarity through their effect on seed bank richness were included, because seed bank richness enters into the computation of S-V similarity. Model fit was performed with the R package lavaan (Rosseel, 2012). 
Plant community

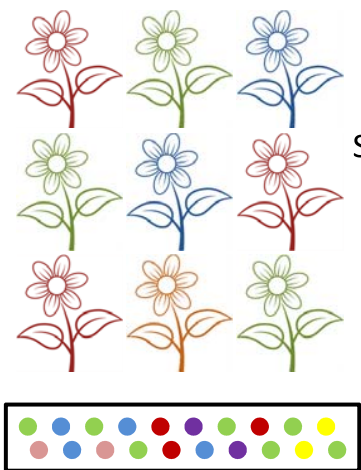

1

Seeding

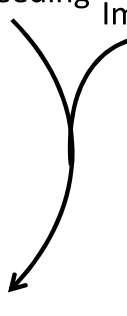

Plant and seed mortality
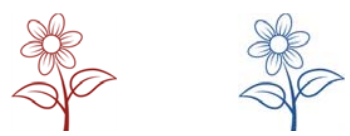

2
Seed bank

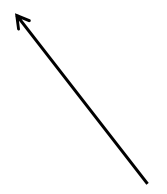

mmigration
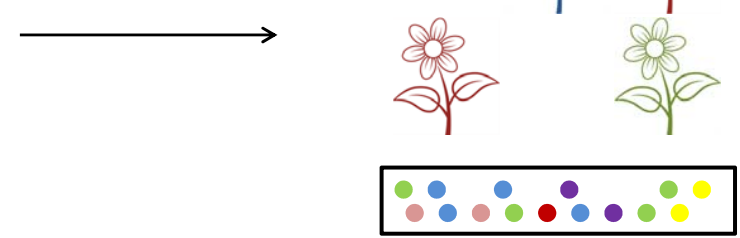

3

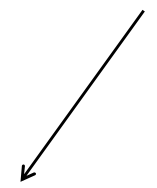

Plant recruitment

FIGURE 2 Model description

\section{3 | A time-averaged neutral model with a seed bank}

We modelled the dynamics of a plant community of $J$ individuals and of its associated seed bank (Figure 2). At each annual time step $t$, each plant individual of species $i$ produces a number $p \times f_{i}(t)$ of seeds, where $p$ is the community-average seed production per individual and $f_{i}(t)$ represents the fertility of species $i$ at time step $t$ relative to this community average. Values of $f_{i}(t)$ are independently drawn from a lognormal distribution with mean 1 and variance $V$. When this variance $V$ is null, the model is neutral in the sense that all plant individuals are exchangeable at each time step, irrespective of the species to which they belong. When the variance $V$ is strictly positive, plant individuals are no longer exchangeable at a given time step, although they have the same temporally averaged fertility $p$. This is why this type of model is called a time-averaged neutral model (Kalyuzhny et al., 2015). The seeds produced by the plant community contribute to the seed bank, and $i$ additional seeds are also added by immigration from the surrounding regional pool containing $S_{\text {pool }}$ species. The species-abundance distribution in this regional pool is modelled with a log-series distribution with parameter $\theta$ (Hubbell, 2001). This parameter controls the evenness of species abundances in the regional pool. A constant proportion $d_{\text {seed }}$ of the seeds dies between two successive time steps, irrespective of the species to which they belong. Likewise, each plant individual has a fixed probability $d_{\text {plant }}$ of dying at each time step, after having produced its seeds. At the following time step, the $J_{\text {dead }}(t)$ dead plant individuals are replaced by the same number of new individuals randomly recruited from the surviving seeds of the seed bank. Individuals of the different species are drawn with a multinomial distribution, with species-specific probabilities proportional to $s_{i}(t)$, where $s_{i}(t)$ is the number of seeds of species $i$ in the seed bank at time step $t$.

A pseudocode of the model is presented in Supporting Information Appendix S1, and a commented R code to simulate this model of community dynamics was archived on Github at the following address: https://github.com/franckjabot/TNTB_seedbank/tree/v1.

\section{4 | Simulation protocol}

We simulated communities of $J_{p}=100$ plant individuals. The plant community was initialized by a random draw of $J_{p}$ individuals from the regional pool, and the community dynamics was launched for 3,000 time steps, so that a dynamic equilibrium had been reached. Simulations were continued during 2,000 additional time steps, and we recorded various community statistics every 10 time steps, leading to 200 sets of community statistics for each parameter combination. These 200 sets of community statistics were then summarized using averaged values. Community statistics examined were the total species richness $S_{\text {seed }}$ and $S_{\text {plant }}$ of the seed bank and of the plant community, respectively, the seed bank size $N_{\text {seed }}$, the sampled species richness of the seed bank by simulating a sampling of $0.01 \%\left(S_{1}\right), 0.1 \%\left(S_{2}\right)$ and $1 \%$ $\left(S_{3}\right)$ of the seed bank, respectively, and the associated Sorensen similarity (Sor ${ }_{1}$, Sor ${ }_{2}$ and Sor $_{3}$ ) between the sampled seed bank and the plant community. Sorensen similarity was computed as Sor $_{1,2,3}=2 \times C_{1,2,3} /$ $\left(S_{1,2,3}+S_{\text {plant }}\right)$, where $C_{1,2,3}$ is the number of species in common between the sampled seed bank and the plant community. Given that Sorensen similarity uses total species numbers, it is very sensitive to the sampling intensity of the seed bank; therefore, we computed three 
different Sorensen similarity values, Sor ${ }_{1}, \mathrm{Sor}_{2}$ and $\mathrm{Sor}_{3}$, using the three simulated sampling intensities.

We used a full factorial design to explore the model predictions. We varied each parameter widely, so as to ensure that we scanned most biologically reasonable cases. Parameter $p$ of seed production was varied in $\{10 ; 50 ; 250 ; 1,250\}$, which is in line with empirical ranges (e.g., Aarssen \& Taylor, 1992). Note that we did not explore the upper end of this seed production range because of computing time limitations ( $N_{\text {seed }}$ already reached 2,500,000 in some simulations with $p$ equal to 1,250$)$. Parameter $d_{\text {seed }}$ of seed mortality was varied in $\{0.05 ; 0.1 ; 0.2 ; 0.4\}$, leading to an average seed life span in the soil between 2.5 and 20 years, which encompasses seed longevities commonly reported (Bekker et al., 1998). Parameter $d_{\text {plant }}$ of plant mortality was varied in $\{0.03 ; 0.1 ; 0.3 ; 1\}$, which encompasses the cases of annual plants and of long-lived (c. 30 years) perennial ones (Hara \& Herben, 1997). Parameter $i$ of the annual number of immigrating seeds was varied in $\{10 ; 50 ; 250 ; 1,250\}$, which leads to a range of cases from very strongly dispersal-limited communities ( $i$ small and $p$ large) to almost dispersal-unlimited communities (i large and $p$ small). Parameter $S_{\text {pool }}$ of regional pool richness was varied in $\{10 ; 25 ; 50 ; 100\}$. This range is below the empirically observed values reported in Supporting Information Appendix S2, but it was chosen for computing time limitations. As we are interested in qualitative model behaviour, this underestimated range should not be problematical. Parameter $\theta$ of regional diversity was varied in $\{1 ; 5 ; 25 ; 125\}$. These values are in line with previous studies on neutral models (e.g., Jabot \& Chave, 2009). We further checked that this range of $\theta$ values lead to widely variable evenness values in the pool, from c. 0.3 to 0.9 , whatever the richness of the pool (Supporting Information Table S1). Finally, we varied parameter $V$ of environmental variance in $\{0 ; 0.1$; $0.3 ; 1\}$, which is in line with previous studies on time-averaged neutral models (Jabot \& Lohier, 2016; Kalyuzhny et al., 2015). Note that the case $V=0$ refers to a strictly neutral model without environmental stochasticity. This full factorial design leads to a total of $4^{7}=16,384$ simulations, among which 4,096 were strictly neutral, and 12,288 were time-averaged neutral. Model simulation results are provided in Supporting Information Appendix S3.

We finally assessed whether empirical findings were consistent with the predictions of the strictly neutral and time-averaged neutral models of plant community dynamics with a seed bank. In these comparisons, seed bank density was $\log _{10}$-transformed in both empirical and simulation analyses. The effect of the $\log _{10}$-transformed sampling area in empirical studies was compared with the effect of sampling intensity in simulation studies. Strictly speaking, these two quantities are comparable only under the assumption that the seed bank is well mixed. However, most empirical studies pool several seed bank samples, thereby minimizing the potential bias linked to seed bank spatial structuring. $\log _{10}$-transformed regional pool richness was used in both empirical and simulation analyses. The effect of the $\log _{10}$-transformed coefficient of variation in the number of wet days in empirical analyses was compared with the effect of the $\log _{10}$-transformed environmental variance $A$ in the time-averaged neutral model.

\section{3 | RESULTS}

\section{1 | Empirical macroecological patterns}

Based on our analysis of published studies, we first found evidence for a latitudinal gradient in both seed bank richness (Figure 3a; $R^{2}=0.10$, $p<.001, n=121$ ) and S-V similarity (Figure $3 b ; R^{2}=0.07, p=.003$, $n=130$ ). We then assessed whether these latitudinal gradients may be explained by among-site variations in environmental variability, regional pool richness, seed bank density and sampling area. Among these four putative drivers, environmental variability was the most strongly correlated with latitude (Cor $=-0.63$; Supporting Information Table S2), whereas the three other tested drivers were less correlated with latitude (|Cor| c. 0.2; Supporting Information Table S2). We found that the four tested covariables were indeed significantly linked to variations in seed bank richness and S-V similarity (Figure 4; Supporting Information Table S4). All four tested drivers had similar magnitudes of effects on both seed bank richness and S-V similarity, highlighting that seed bank macroecological patterns are driven not only by environmental variability, but also by the density of the seed bank, the intensity of seed bank sampling, and biogeographical effects linked to the size of the regional species pool.

\subsection{Consistency with the predictions of the neutral models with a seed bank}

We then assessed whether these empirical findings were consistent with the predictions of the strictly neutral and time-averaged neutral models of plant community dynamics with a seed bank. We found a striking agreement between theoretical predictions and empirical observations for six of the eight correlations of Figure 4 with both the strictly neutral and the time-averaged neutral models (Figure 5). Below, we detail the model results for seed bank richness and S-V similarity in turn.

First, we recovered in model simulations that seed bank density was positively correlated with sampled seed bank richness $S_{2}$ at intermediate sampling intensity (Figure $5 \mathrm{a} ; R^{2}=0.03$ ). This result was also recovered at low $\left(R^{2}=0.20\right)$ and high $\left(R^{2}=0.003\right)$ sampling intensities, and was similar when looking separately at strictly neutral and timeaveraged neutral simulations. The effect size of these relationships decreases with sampling intensity. Second, sampling intensity was found to have a positive impact on seed bank richness, for both strictly neutral and time-averaged neutral simulations (Figure $5 \mathrm{~b}$; average increases in seed bank richness of 2.5 and 6.6 species when sampling intensity increases from 0.01 to 0.1 and $1 \%$, respectively, in the strictly neutral model, and of 2.4 and 6.5 species in the time-averaged neutral model; all paired Wilcoxon tests $p$-value $<10^{-15}$ ). Third, regional pool richness $S_{\text {pool }}$ was found to have a weak positive impact on sampled seed bank richness $S_{2}$ in most simulations of both strictly neutral and timeaveraged neutral models (Figure $5 \mathrm{c}$; average increases in seed bank richness of $1.1,1.5$ and 1.7 species when $S_{\text {pool }}$ increases from 10 to 25,50 and 100, respectively, in the strictly neutral model, and of 1, 1.4 and 1.5 species in the time-averaged neutral model; all paired Wilcoxon tests $p$ value $<10^{-5}$ ). Similar results were obtained when considering sampled 

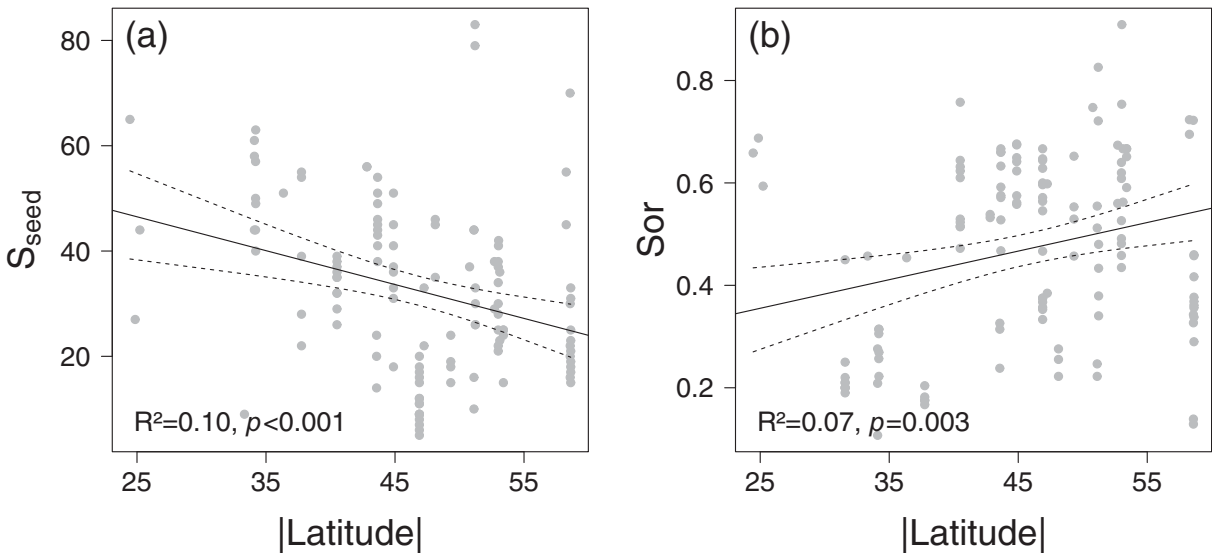

FIGURE 3 Latitudinal gradients of seed bank richness and seed bank-vegetation similarity. (a) Seed bank richness $\left(S_{\text {seed }}\right)$. (b) Sorensen index (Sor) of similarity between seed bank and aboveground vegetation. Full regression results are provided in Supporting Information Table S3. Regression lines (continuous) and their confidence intervals (dashed) are depicted

seed bank richness at low and large sampling intensities (Supporting Information Figures S12 and S13).

First, seed bank-vegetation similarity was found to have a unimodal relationship with seed bank density (Figure $5 d$ ). More precisely, this relationship was strictly positive at low sampling intensities (Supporting Information Figure S12e) and progressively turned to unimodal at increasing sampling intensities (Figure $5 \mathrm{~d}$; Supporting Information Figure S13e). Second, sampling intensity was found to have a positive but saturating effect on S-V similarity for both the strictly neutral and the time-averaged neutral models (Figure 5e; average increases in $\mathrm{Sor}_{2}$ of 0.14 when sampling intensity increases from 0.01 to 0.1 or $1 \%$ in both the strictly neutral model and the time-averaged neutral model; all paired Wilcoxon tests $p$-value $<10^{-15}$ ). These results can be

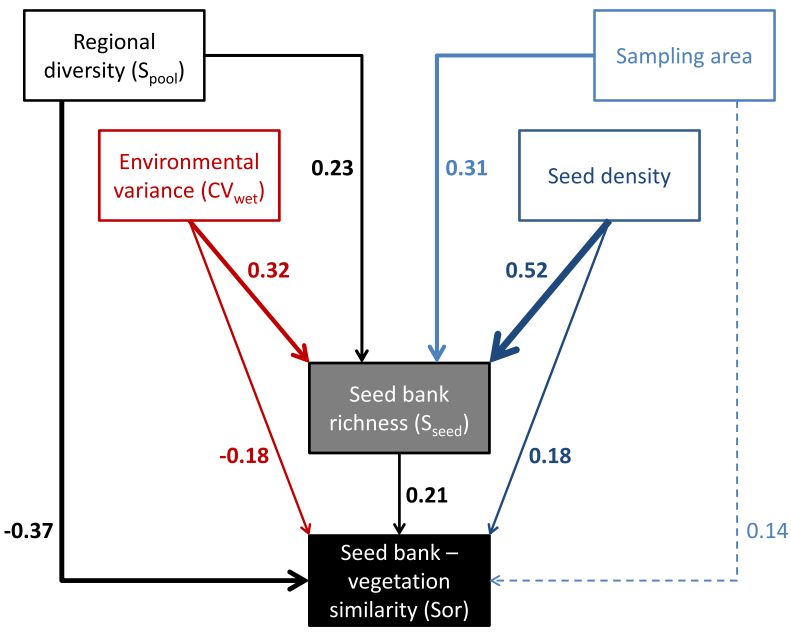

FIGURE 4 Structural equation modelling of seed bank richness and seed bank-vegetation similarity. All the plain arrows correspond to significant $(p<.05)$ relationships, whereas the dashed arrow corresponds to a non-significant trend $(p=.09)$. Arrow widths represent the magnitude of standardized regression coefficients that are also mentioned next to the arrows. All $p$-values and summary of direct, indirect and total effects of the four drivers are reported in Supporting Information Table S4 understood as follows: large seed banks are storing species that are not present in the established community. As a larger number of seeds are sampled, either because of a larger seed bank density (Figure $5 d$ ) or because of a larger percentage of the seed bank that is sampled (Figure $5 e), S-V$ similarity first increases because the species present in the established community are progressively sampled in the seed bank (Supporting Information Figure S14a). But as the number of seeds sampled continues to increase, new species that are not present in the adult community are progressively recovered in the seed bank, thereby decreasing S-V similarity (Supporting Information Figure S14b,c). The median sampling intensity in empirical studies, which we define as the ratio of the seed bank sampling area on the plant sampling area, was equal to $0.95 \%$, which is close to the high-intensity case modelled (i.e. 1\%). This is likely to explain the milder effect of seed density on S-V similarity found in empirical studies, compared with its effect on seed bank richness and why sampling area was found to have a positive but non-significant effect on S-V similarity in empirical studies (Figure 4). Third, regional pool richness $S_{\text {pool }}$ was found to have a weak negative impact on S-V similarity in most simulations of both strictly neutral and time-averaged neutral models (Figure 5f; average decreases in $\mathrm{Sor}_{2}$ of $0.048,0.065$ and 0.069 when $S_{\text {pool }}$ increases from 10 to 25,50 and 100 , respectively, in the strictly neutral model, and of $0.044,0.059$ and 0.066 in the time-averaged neutral model; all paired Wilcoxon tests $p$-value $<.0003)$. Similar results were obtained when considering sampled seed bank richness at low and large sampling intensities (Supporting Information Figures S12 and S13).

\subsection{Additional predictions of the time-averaged neutral model}

The strictly neutral model did not make any prediction regarding the effect of environmental variance that is not taken into account in this model. The predictions of the time-averaged neutral model regarding the effect of environmental variance were partly in line with empirical observations. More precisely, environmental variance $V$ was found to have variable effects on seed bank richness $S_{2}$, depending on model 
(a)

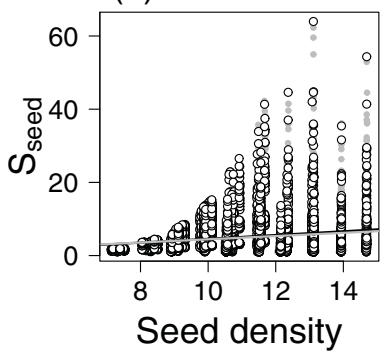

(d)

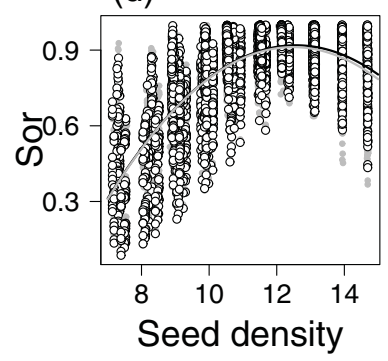

(b)

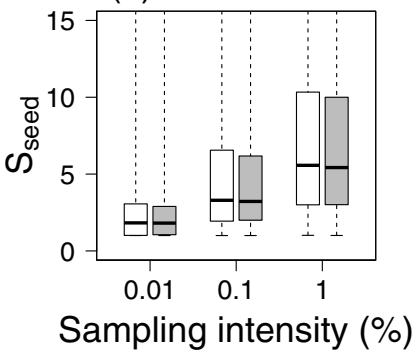

(e)

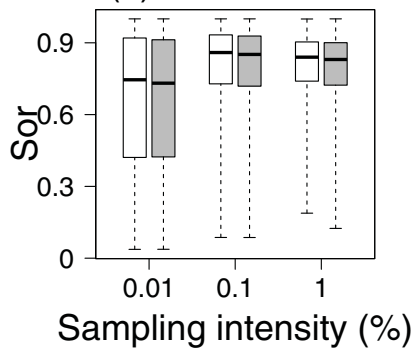

$\square$ time-averaged neutral model

(c)

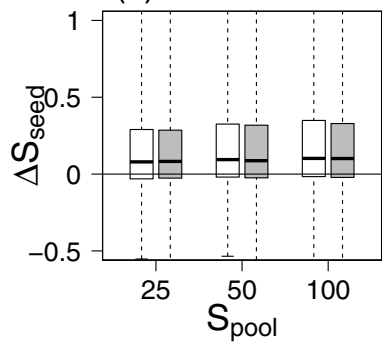

(f)

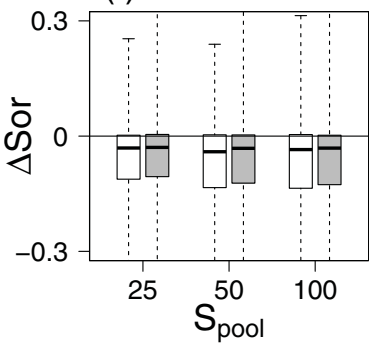

FIGURE 5 Predictions of the strictly neutral and time-averaged neutral models. (a-c) Effects of (a) seed density, (b) sampling intensity and (c) regional pool richness on seed bank richness $\left(S_{\text {seed }}\right)$ in model simulations. (d-f) Effects of the same parameters on seed bank-vegetation (S-V) similarity (Sor). $S_{\text {seed }}$ and Sor are based on a sampling of $0.1 \%$ of the seed bank in (a, c, d, f). Seed density is measured by $\ln \left(\mathrm{N}_{\text {seed }}\right)$. $\Delta S_{\text {seed }}$ is the relative variation in sampled seed bank richness $S_{\text {seed }}$ caused by an increase in the $S_{\text {pool }}$ parameter from its minimal value (10) to a larger value $(25,50$ or 100$)$, all the other model parameters being fixed. $\Delta$ Sor is defined in a similar manner for the Sor index. Box plots are partly truncated for clarity in (b, c, f). Full box plot ranges are depicted in Supporting Information Figure S11

parameter combinations (Figure 6a). Positive effects were recovered for simulations with low plant mortality $d_{\text {plant }}$ and large seed mortality $d_{\text {seed }}$ (Figure 6a; Supporting Information Table S5). These parameter values correspond to scenarios for grasslands dominated by perennial plants (low $d_{\text {plant }}$ ) with modest seed longevity (Stöcklin \& Fischer, 1999). In contrast, the positive effect of $V$ on $S$ was not recovered when $d_{\text {plant }}$ was high and $d_{\text {seed }}$ low (Supporting Information Table S5). This latter combination of parameter values corresponds to scenarios for grasslands dominated by annual plants. Other model parameters had lower impacts on this relationship (Supporting Information Tables S7 and S9).

Likewise, environmental variance was found to have variable effects on S-V similarity (Figure 6b; Supporting Information Table S6), depending on the subdomains of the parameter space considered. The negative effects highlighted from empirical studies were recovered for simulations with high plant mortality $d_{\text {plant }}$ and low seed mortality $d_{\text {seed, }}$, which corresponds to grasslands dominated by annuals. In contrast, in the case of grasslands dominated by perennials (low $d_{\text {plant }}$ and high $d_{\text {seed }}$ ), simulations did not recover the empirical patterns (Supporting Information Table S6). Other model parameters had lower impacts on this relationship (Supporting Information Tables S8 and S10).

\section{4 | DISCUSSION}

Our study found evidence, for the first time to our knowledge, of a weak latitudinal gradient in seed bank richness and seed bankvegetation similarity, with a smaller richness and a larger S-V similarity at higher latitudes (Figure 3). This finding adds to the already numerous latitudinal gradients evidenced for biodiversity patterns in general (Willig, Kaufman, \& Stevens, 2003). For terrestrial plants, a number of latitudinal gradients have been demonstrated concerning aboveground species richness (Gentry, 1988; Silvertown, 1985), beta diversity (Qian \& Ricklefs, 2007), biotic interactions (Schemske, Mittelbach, Cornell, Sobel, \& Roy, 2009), assembly rules (Qiao, Jabot, Tang, Jiang, \& Fang, 2015), evolutionary rates (Davies, Savolainen, Chase, Moat, \& Barraclough, 2004) and phylogenetic diversity (Kerkhoff, Moriarty, \& Weiser, 2014). A latitudinal gradient in seed size has also been evidenced, with plants having larger seeds in the tropics (Moles, Ackerly, \& Tweddle, 2007). The new macroecological patterns evidenced here are particularly interesting in that they stress the importance of metacommunity processes to understand seed bank patterns. Besides, the large remaining variability around these latitudinal gradients calls for an integrated explanation of seed bank diversity patterns mobilizing both regional and local processes.

Indeed, the field of seed bank ecology has been mainly focused on the impacts of environmental variability on the recruitment of plants from the seed banks (Facelli et al., 2005; Grubb, 1977; Warner \& Chesson, 1985). From this research tradition follows the view of seed banks as biodiversity reservoirs whose patterns may be crucially impacted by environmental variability (Faist, Ferrenberg, \& Collinge, 2013; Thompson \& Grime, 1979; Vandvik et al., 2015). Our results recover this view, but they also point out that major macroecological seed bank patterns are partly attributable to processes acting at the metacommunity scale, with both the diversity of the regional pool and the 
$\square$ all simulations

(a)

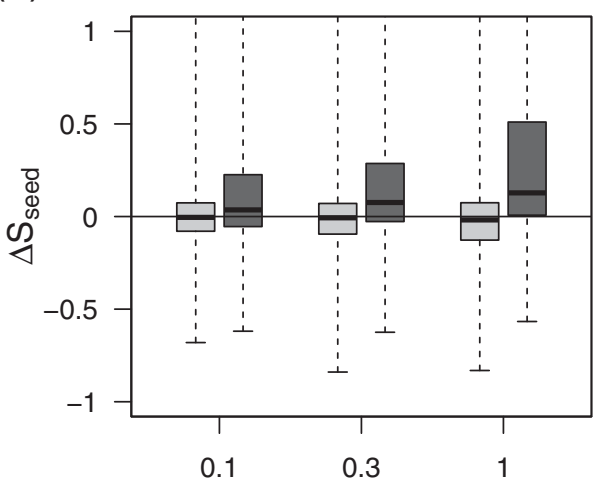

(b) $\square$ all simulations

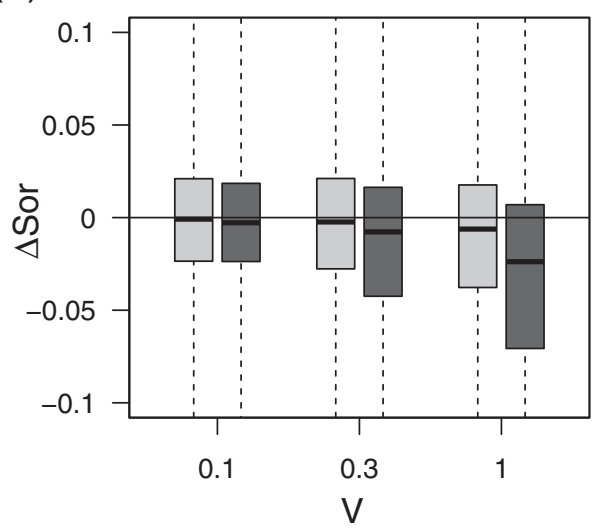

FIGURE 6 Effect of environmental variance in the time-averaged neutral model. Effects of the environmental variance parameter (V) on (a) seed bank richness and (b) seed bank-vegetation ( $\mathrm{S}$-V) similarity. $\Delta S_{\text {seed }}$ and $\Delta$ Sor are defined as in Figure 5. Dark grey boxes of (a) correspond to a subset of model simulations for which parameters $d_{\text {seed }}=0.4$ and $d_{\text {plant }}=0.03$ (communities of perennials). They correspond in (b) to simulations with $d_{\text {seed }}=0.05$ and $d_{\text {plant }}=1$ (communities of annuals). Box plots are partly truncated for clarity. Full box plot ranges are depicted in Supporting Information Figure S11

immigration rate from this pool having impacts on the similarity between seed banks and aboveground vegetation (Figure 4).

Another important result of our study is that, on top of metacommunity processes, seed bank density and sampling area are likely to have significant impacts on seed bank patterns by being positively correlated with sampled species richness and S-V similarity (Figures 4 and $5 a, b, d, e)$. This is consistent with the recent conclusions of Vandvik et al. (2015) based on their study of species-area relationships of seed banks. Both the strictly neutral and the time-averaged neutral models further predicted that the positive relationship between seed bank density and S-V similarity turned to unimodal for very large seed densities and at medium and high sampling intensities (Figure 5e; Supporting Information Figure S13e). This phenomenon is attributable to a progressive sampling in the seed bank of species not present in the established plant community (Supporting Information Figure S14).
It may explain the somewhat milder effects of seed density and sampling area on S-V similarity found in empirical studies (Figure 4). These results stress the need to standardize empirical findings cautiously when performing comparisons of seed bank patterns across studies, because sampling and density effects are at least as important as environmental and regional processes in shaping seed bank patterns (Figure 4). Interestingly, such sampling effects provide a potential explanation for the general pattern of larger S- $\mathrm{V}$ similarity in grasslands compared with forests (Bossuyt \& Honnay, 2008). Indeed, these authors compiled published seed bank studies and found evidence of this pattern, but also that grasslands tended to have a larger seed density and diversity. The larger S-V similarity of grasslands compared with forests could thus be solely attributable to a sampling effect.

The large influence of biogeographical factors and of sampling processes on seed bank diversity patterns is further confirmed by the agreement between six of the eight empirical correlations found in our analyses of published data (Figure 4) and the predictions from both a strictly neutral model and a time-averaged neutral model (Figure 5). The positive correlation between environmental variability and seed bank richness was further recovered with the time-averaged neutral model, in the subdomain of the parameter space corresponding to long-lived perennial plants with modest seed longevity in the seed bank (Figure 6a; Supporting Information Table S5). The last negative correlation between environmental variability and seed bankvegetation similarity was recovered in model simulations only in the subdomain of the parameter space corresponding to annual plants (Figure 6b). It is worth noting that this negative effect was not strong in our data analysis, possibly because the set of empirical studies mixes both sites dominated by perennials, such as temperate and mountainous grasslands, and sites dominated by annuals, such as Mediterranean fields. In addition, the observed relationship between S-V similarity and environmental variance was partly annealed by the positive indirect effect of seed bank richness (Figure 4). We therefore contend that more empirical comparisons with better controlled protocols should be conducted before a definitive assessment of the time-averaged neutral model can be made on this particular pattern. Besides, it is worth noting that the studied responses of seed bank richness and of its similarity with aboveground vegetation are not mutually independent, as evidenced by the structural equation model (Figure 4). Therefore, the cumulative evidence brought by the eight investigated relationships should somehow be tempered. Nonetheless, our results support a clear influence of strictly neutral processes on the structuring of seed bank diversity patterns, although environmental variability does contribute positively to seed bank diversity.

Given the large variability among studies in sampling protocols, biogeographical and ecological contexts, our comparison between model predictions and empirical patterns was restricted to qualitative analyses. In this perspective, we explored the predictions of the two models on a large range of parameter values, so as to obtain broad and qualitatively robust predictions. The downside of this simulation approach is that we typically obtained modest correlations when analysing the univariate influence of the four tested drivers on model outputs (Figure 5). 
Importantly, these modest effect sizes should not be interpreted as meaning that the various drivers have a modest influence on seed bank patterns, but rather that these influences are interacting and nonlinear. In line with this interpretation, the structural equation modelling analysis reached relatively large $R^{2}$ (0.35 and 0.32; see Supporting Information Table S4). Nonetheless, an interesting perspective would be to focus on more standardized empirical data in order to infer the parameters of the time-averaged neutral model quantitatively. This would allow a finer quantification of the respective influences of dispersal, drift and environmental variability on seed bank and plant diversity patterns. Such analyses have been performed recently with a time-averaged neutral model without a seed bank (Jabot \& Lohier, 2016) using approximate Bayesian techniques (Beaumont, 2010; Lagarrigues, Jabot, Lafond, \& Courbaud, 2015). These same techniques could easily be extended to the present model with a seed bank. Such quantitative inferences would be of great interest for conservation purposes, because the diversity of seed banks and their similarity with aboveground vegetation are crucial properties to stabilize local communities through rescue effects (Piessens, Honnay, Nackaerts, \& Hermy, 2004).

From a more theoretical perspective, our study offers an extension of strictly neutral and time-averaged neutral models by explicitly modelling the coupled dynamics of the seed bank. It therefore offers a theoretical framework to study seed bank diversity patterns and the impact of seed banks on plant community dynamics in a metacommunity context. Our simple approach to modelling coupled metacommunities of seed banks and plants is especially timely, because recent evidence suggests that anthropogenic impacts on plant communities may also occur indirectly through seed banks (Basto et al., 2015). It is thus important to develop integrated spatial theory to understand this coupled dynamics of seed banks and vegetation in a metacommunity context (Vandvik \& Goldberg, 2006). Time-averaged neutral models are particularly appealing, because they enable the effect of environmental variability on plant dynamics to be taken into account (Pake \& Venable, 1996) within an economical modelling framework. This approach extends previous work on lottery competitive systems (Chesson \& Warner, 1981; Fagerström, 1988) by considering the effect of dispersal limitation on top of environmental variability, thereby connecting seed bank and metacommunity ecology.

We have documented two latitudinal gradients in seed bank richness and seed bank-vegetation similarity, and we have provided an explanation for these patterns, rooted in metacommunity ecology (Holyoak, Leibold, \& Holt, 2005). But many other seed bank macroecological patterns still need general explanations that may need further elaborations beyond this neutral framework. For instance, the impact of disturbances on seed bank dynamics has been recurrently studied with directional trends in seed bank composition following disturbance (Falińska, 1999; Helsen, Hermy, \& Honnay, 2015; Royo \& Ristau, 2013) and different similarity trends in grasslands and forests (Hopfensperger, 2007). To study such other general patterns, it may be necessary to include additional ingredients to this time-averaged neutral framework, such as multiple guilds, as has been done for strictly neutral models (Janzen, Haegeman, \& Etienne, 2015; Scheffer \& Van
Nes, 2006), but also bud banks (Klimešová \& Klimeš, 2007; Vesk \& Westoby, 2004) or seed trade-offs (Muller-Landau, 2010). Such elaborations on this neutral framework may enable the study of the dynamical consequences of these various ecological ingredients and deepen our understanding of seed bank metacommunities.

\section{ACKNOWLEDGMENTS}

We thank Brian Enquist, Allen Hurlbert and an anonymous referee for their constructive comments that considerably improved the manuscript.

\section{ORCID}

Franck Jabot (iD) http://orcid.org/0000-0002-3113-9510

\section{REFERENCES}

Aarssen, L. W., \& Taylor, D. R. (1992). Fecundity allocation in herbaceous plants. Oikos, 65, 225-232.

Bakker, J. P., \& Berendse, F. (1999). Constraints in the restoration of ecological diversity in grassland and heathland communities. Trends in Ecology and Evolution, 14, 63-68.

Baskin, C. C., \& Baskin, J. M. (2001). Seeds: Ecology, biogeography, and evolution of dormancy and germination. San Diego, CA: Academic Press.

Basto, S., Thompson, K., Phoenix, G., Sloan, V., Leake, J., \& Rees, M. (2015). Long-term nitrogen deposition depletes grassland seed banks. Nature Communications, 6, 6185.

Beaumont, M. A. (2010). Approximate Bayesian computation in evolution and ecology. Annual Review of Ecology, Evolution, and Systematics, 41, 379-406.

Bekker, R. M., Bakker, J. P., Grandin, U., Kalamees, R., Milberg, P., Poschlod, P., ... Willems, J. H. (1998). Seed size, shape and vertical distribution in the soil: Indicators of seed longevity. Functional Ecology, 12, 834-842.

Bekker, R. M., Verweij, G. L., Bakker, J. P., \& Fresco, L. F. (2000). Soil seed bank dynamics in hayfield succession. Journal of Ecology, 88, 594-607.

Bonis, A., Lepart, J., \& Grillas, P. (1995). Seed bank dynamics and coexistence of annual macrophytes in a temporary and variable habitat. Oikos, 74, 81-92

Bossuyt, B., \& Hermy, M. (2001). Influence of land use history on seed banks in European temperate forest ecosystems: A review. Ecography, 24, 225-238.

Bossuyt, B., \& Honnay, O. (2008). Can the seed bank be used for ecological restoration? An overview of seed bank characteristics in European communities. Journal of Vegetation Science, 19, 875-884.

Chesson, P. (2000). Mechanisms of maintenance of species diversity. Annual Review of Ecology and Systematics, 31, 343-366.

Chesson, P. L., \& Warner, R. R. (1981). Environmental variability promotes coexistence in lottery competitive systems. The American Naturalist, 117, 923-943.

Condit, R., Pitman, N., Leigh, E. G., Jr, Chave, J., Terborgh, J., Foster, R. B., ... Hubbell, S. P. (2002). Beta-diversity in tropical forest trees. Science, 295, 666-669.

Davies, T. J., Savolainen, V., Chase, M. W., Moat, J., \& Barraclough, T. G. (2004). Environmental energy and evolutionary rates in flowering plants. Proceedings of the Royal Society B: Biological Sciences, 271, 2195-2200. 
Ellis, E. C., Antill, E. C., \& Kreft, H. (2012). All is not loss: Plant biodiversity in the Anthropocene. PLoS One, 7, e30535.

Facelli, J. M., Chesson, P., \& Barnes, N. (2005). Differences in seed biology of annual plants in arid lands: A key ingredient of the storage effect. Ecology, 86, 2998-3006.

Fagerström, T. (1988). Lotteries in communities of sessile organisms. Trends in Ecology and Evolution, 3, 303-306.

Faist, A. M., Ferrenberg, S., \& Collinge, S. K. (2013). Banking on the past: Seed banks as a reservoir for rare and native species in restored vernal pools. AoB Plants, 5, plt043.

Falińska, K. (1999). Seed bank dynamics in abandoned meadows during a 20-year period in the Białowieża National Park. Journal of Ecology, 87, 461-475.

Gentry, A. H. (1988). Changes in plant community diversity and floristic composition on environmental and geographical gradients. Annals of the Missouri Botanical Garden, 75, 1-34.

Gotelli, N. J., \& Graves, G. R. (1996). Null models in ecology. Washington, DC and London, U.K.: Smithsonian Institution Press.

Grubb, P. J. (1977). The maintenance of species-richness in plant communities: The importance of the regeneration niche. Biological Reviews, 52, 107-145.

Hara, T., \& Herben, T. (1997). Shoot growth dynamics and sizedependent shoot fate of a clonal plant, Festuca rubra, in a mountain grassland. Researches on Population Ecology, 39, 83-93.

Harris, I., Jones, P. D., Osborn, T. J., \& Lister, D. H. (2014). Updated high-resolution grids of monthly climatic observations - the CRU TS3.10 Dataset. International Journal of Climatology, 34, 623-642.

Heck, K. L., Jr, van Belle, G., \& Simberloff, D. (1975). Explicit calculation of the rarefaction diversity measurement and the determination of sufficient sample size. Ecology, 56, 1459-1461.

Helsen, K., Hermy, M., \& Honnay, O. (2015). Changes in the species and functional trait composition of the seed bank during semi-natural grassland assembly: Seed bank disassembly or ecological palimpsest? Journal of Vegetation Science, 26, 58-67.

Henderson, C. B., Petersen, K. E., \& Redak, R. A. (1988). Spatial and temporal patterns in the seed bank and vegetation of a desert grassland community. Journal of Ecology, 76, 717-728.

Holyoak, M., Leibold, M. A., \& Holt, R. D. (2005). Metacommunities: Spatial dynamics and ecological communities. Chicago, IL; University of Chicago Press.

Hopfensperger, K. N. (2007). A review of similarity between seed bank and standing vegetation across ecosystems. Oikos, 116, 1438-1448.

Hubbell, S. P. (2001). The unified neutral theory of biodiversity and biogeography. Princeton, NJ: Princeton University Press.

Ives, A. R., Dennis, B., Cottingham, K. L., \& Carpenter, S. R. (2003). Estimating community stability and ecological interactions from timeseries data. Ecological Monographs, 73, 301-330.

Jabot, F., \& Chave, J. (2009). Inferring the parameters of the neutral theory of biodiversity using phylogenetic information and implications for tropical forests. Ecology Letters, 12, 239-248.

Jabot, F., \& Chave, J. (2011). Analyzing tropical forest tree species abundance distributions using a nonneutral model and through approximate Bayesian inference. The American Naturalist, 178, E37-E47.

Jabot, F., \& Lohier, T. (2016). Non-random correlation of species dynamics in tropical tree communities. Oikos, 125, 1733-1742.

Janzen, T., Haegeman, B., \& Etienne, R. S. (2015). A sampling formula for ecological communities with multiple dispersal syndromes. Journal of Theoretical Biology, 374, 94-106.
Jones, F. A., \& Muller-Landau, H. C. (2008). Measuring long-distance seed dispersal in complex natural environments: An evaluation and integration of classical and genetic methods. Journal of Ecology, 96, 642-652.

Jordano, P. (2017). What is long-distance dispersal? And a taxonomy of dispersal events. Journal of Ecology, 105, 75-84.

Kalyuzhny, M., Kadmon, R., \& Shnerb, N. M. (2015). A neutral theory with environmental stochasticity explains static and dynamic properties of ecological communities. Ecology Letters, 18, 572-580.

Kerkhoff, A. J., Moriarty, P. E., \& Weiser, M. D. (2014). The latitudinal species richness gradient in New World woody angiosperms is consistent with the tropical conservatism hypothesis. Proceedings of the National Academy of Sciences USA, 111, 81258130.

Klimešová, J., \& Klimeš, L. (2007). Bud banks and their role in vegetative regeneration - A literature review and proposal for simple classification and assessment. Perspectives in Plant Ecology, Evolution and Systematics, 8, 115-129.

Kreft, H., \& Jetz, W. (2007). Global patterns and determinants of vascular plant diversity. Proceedings of the National Academy of Sciences USA, 104, 5925-5930.

Lagarrigues, G., Jabot, F., Lafond, V., \& Courbaud, B. (2015). Approximate Bayesian computation to recalibrate individual-based models with population data: Illustration with a forest simulation model. Ecological Modelling, 306, 278-286.

Lande, R., Engen, S., \& Saether, B. E. (2003). Stochastic population dynamics in ecology and conservation. Oxford, U.K.: Oxford University Press.

McGill, B. J., Etienne, R. S., Gray, J. S., Alonso, D., Anderson, M. J., Benecha, H. K., ... \& White, E. P. (2007). Species abundance distributions: Moving beyond single prediction theories to integration within an ecological framework. Ecology Letters, 10, 995-1015.

Moles, A. T., Ackerly, D. D., Tweddle, J. C., Dickie, J. B., Smith, R., Leishman, M. R., ... Westoby, M. (2007). Global patterns in seed size. Global Ecology and Biogeography, 16, 109-116.

Muller-Landau, H. C. (2010). The tolerance-fecundity trade-off and the maintenance of diversity in seed size. Proceedings of the National Academy of Sciences USA, 107, 4242-4247.

Pake, C. E., \& Venable, D. L. (1996). Seed banks in desert annuals: Implications for persistence and coexistence in variable environments. Ecology, 77, 1427-1435.

Piessens, K., Honnay, O., Nackaerts, K., \& Hermy, M. (2004). Plant species richness and composition of heathland relics in north-western Belgium: Evidence for a rescue-effect? Journal of Biogeography, 31, 1683-1692.

Plotkin, J. B., Potts, M. D., Leslie, N., Manokaran, N., LaFrankie, J., \& Ashton, P. S. (2000). Species-area curves, spatial aggregation, and habitat specialization in tropical forests. Journal of Theoretical Biology, 207, 81-99.

Qian, H., \& Ricklefs, R. E. (2007). A latitudinal gradient in large-scale beta diversity for vascular plants in North America. Ecology Letters, 10, 737-744.

Qiao, X., Jabot, F., Tang, Z., Jiang, M., \& Fang, J. (2015). A latitudinal gradient in tree community assembly processes evidenced in Chinese forests. Global Ecology and Biogeography, 24, 314-323.

Rosindell, J., Hubbell, S. P., \& Etienne, R. S. (2011). The unified neutral theory of biodiversity and biogeography at age ten. Trends in Ecology and Evolution, 26, 340-348.

Rosseel, Y. (2012). lavaan: An R package for structural equation modeling. Journal of Statistical Software, 48, 1-36. 
Royo, A. A., \& Ristau, T. E. (2013). Stochastic and deterministic processes regulate spatio-temporal variation in seed bank diversity. Journal of Vegetation Science, 24, 724-734.

Scheffer, M., \& van Nes, E. H. (2006). Self-organized similarity, the evolutionary emergence of groups of similar species. Proceedings of the National Academy of Sciences USA, 103, 6230-6235.

Schemske, D. W., Mittelbach, G. G., Cornell, H. V., Sobel, J. M., \& Roy, K. (2009). Is there a latitudinal gradient in the importance of biotic interactions? Annual Review of Ecology, Evolution, and Systematics, 40, 245-269.

Silvertown, J. (1985). History of a latitudinal diversity gradient: Woody plants in Europe 13,000-1000 years BP. Journal of Biogeography, 12, 519-525.

Slatkin, M. (1974). Hedging one's evolutionary bets. Nature, 250, 704-705.

Stöcklin, J., \& Fischer, M. (1999). Plants with longer-lived seeds have lower local extinction rates in grassland remnants 1950-1985. Oecologia, 120, 539-543.

Thompson, K., Bakker, J. P., \& Bekker, R. M. (1997). The soil seed banks of North West Europe: Methodology, density and longevity. Cambridge, U.K.: Cambridge University Press.

Thompson, K., \& Grime, J. P. (1979). Seasonal variation in the seed banks of herbaceous species in ten contrasting habitats. Journal of Ecology, 67, 893-921.

Vandvik, V., \& Goldberg, D. E. (2006). Sources of diversity in a grassland metacommunity: Quantifying the contribution of dispersal to species richness. The American Naturalist, 168, 157-167.

Vandvik, V., Klanderud, K., Meineri, E., Måren, I. E., \& Töpper, J. (2015). Seed banks are biodiversity reservoirs: Species-area relationships above versus below ground. Oikos, 125, 218-228.

Venable, D. L. (2007). Bet hedging in a guild of desert annuals. Ecology, 88, 1086-1090.

Vesk, P. A., \& Westoby, M. (2004). Funding the bud bank: A review of the costs of buds. Oikos, 106, 200-208.
Volkov, I., Banavar, J. R., Hubbell, S. P., \& Maritan, A. (2003). Neutral theory and relative species abundance in ecology. Nature, 424, 1035-1037.

Warner, R. R., \& Chesson, P. L. (1985). Coexistence mediated by recruitment fluctuations: A field guide to the storage effect. The American Naturalist, 125, 769-787.

Willig, M. R., Kaufman, D. M., \& Stevens, R. D. (2003). Latitudinal gradients of biodiversity: Pattern, process, scale, and synthesis. Annual Review of Ecology, Evolution, and Systematics, 34, 273-309.

\section{BIOSKETCHES}

FrANCK JABOT is a researcher at Irstea Clermont-Ferrand. He is mainly interested in ecological theory and modelling, with a special focus on plant community ecology, individual-based modelling and statistical inference.

Julien Pottier is a researcher at Inra Clermont-Ferrand. He is mainly interested in spatial ecology and community ecology, with a special focus on grassland systems.

\section{SUPPORTING INFORMATION}

Additional Supporting Information may be found online in the supporting information tab for this article.

How to cite this article: Jabot F, Pottier J. Macroecology of seed banks: The role of biogeography, environmental stochasticity and sampling. Global Ecol Biogeogr. 2017;26:1247-1257. https://doi.org/10.1111/geb.12631 